\title{
Clinical pharmacokinetics of quinine
} and its relationship with treatment outcomes in children, pregnant women, and elderly patients, with uncomplicated and complicated malaria: a systematic review

\author{
Teerachat Saeheng ${ }^{1}$ and Kesara Na-Bangchang ${ }^{1,2^{*}}$
}

\begin{abstract}
Background: Standard dosage regimens of quinine formulated for adult patients with uncomplicated and complicated malaria have been applied for clinical uses in children, pregnant women, and elderly. Since these populations have anatomical and physiological differences from adults, dosage regimens formulated for adults may not be appropriate. The study aimed to (i) review existing information on the pharmacokinetics of quinine in children, pregnant women, and elderly populations, (ii) identify factors that influence quinine pharmacokinetics, and (iii) analyse the relationship between the pharmacokinetics and treatment outcomes (therapeutic and safety) of various dosage regimens of quinine.
\end{abstract}

Methods: Web of Sciences, Cochrane Library, Scopus, and PubMed were the databases applied in this systematic search for relevant research articles published up to October 2020 using the predefined search terms. The retrieved articles were initially screened by titles and abstracts to exclude any irrelevant articles and were further evaluated based on full-texts, applying the predefined eligibility criteria. Excel spreadsheet (Microsoft, WA, USA) was used for data collection and management. Qualitative data are presented as numbers and percentages, and where appropriate, mean + SD or median (range) or range values.

Results: Twenty-eight articles fulfilled the eligibility criteria, 19 in children, 7 in pregnant women, and 2 in elderly (14 and 7 articles in complicated and uncomplicated malaria, respectively). Severity of infection, routes of administration, and nutritional status were shown to be the key factors impacting quinine pharmacokinetics in these vulnerable groups.

Conclusions: The recommended dosages for both uncomplicated and complicated malaria are, in general, adequate for elderly and children with uncomplicated malaria. Dose adjustment may be required in pregnant women with both uncomplicated and complicated malaria, and in children with complicated malaria. Pharmacokinetics studies

\footnotetext{
*Correspondence: kesaratmu@yahoo.com

${ }^{1}$ Center of Excellence in Pharmacology and Molecular Biology of Malaria and Cholangiocarcinoma, Chulabhorn International College, Thammasat University, Rangsit Campus, 99 Moo 18 Phaholyothin Road, Klong Luang District, Pathumthani 12121, Thailand
}

Full list of author information is available at the end of the article

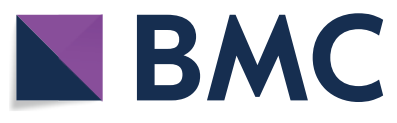

(c) The Author(s) 2022. Open Access This article is licensed under a Creative Commons Attribution 4.0 International License, which permits use, sharing, adaptation, distribution and reproduction in any medium or format, as long as you give appropriate credit to the original author(s) and the source, provide a link to the Creative Commons licence, and indicate if changes were made. The images or other third party material in this article are included in the article's Creative Commons licence, unless indicated otherwise in a credit line to the material. If material is not included in the article's Creative Commons licence and your intended use is not permitted by statutory regulation or exceeds the permitted use, you will need to obtain permission directly from the copyright holder. To view a copy of this licence, visit http://creativecommons.org/licenses/by/4.0/. The Creative Commons Public Domain Dedication waiver (http://creativeco mmons.org/publicdomain/zero/1.0/) applies to the data made available in this article, unless otherwise stated in a credit line to the data. 
relevant to clinical efficacy in these vulnerable groups of patients with large sample size and reassessment of MIC (minimum inhibitory concentration) should be considered.

Keywords: Pharmacokinetics, Quinine, Pregnancy, Children, Elderly, Systematic-review

\section{Background}

Parenteral artesunate, followed by artemisinin-based combination therapy (ACT), is the recommended treatment for severe malaria, when available. Quinine is usually used if artesunate is not available, and is always used in combination with an additional agent, such as doxycycline [1]. Quinine is also used, in combination with clindamycin, for uncomplicated Plasmodium falciparum infections in pregnant women during the first-trimester, as well as for chloroquine-resistant Plasmodium vivax infections [1]. A systematic review in 2012 revealed that artesunate was superior to quinine in reducing mortality rate and adverse drug reactions in severe malaria [2]. A recent systematic review (2020) has suggested a high risk of treatment failure in uncomplicated malaria patients (mostly second- and third-trimester pregnancies) after quinine monotherapy, while the efficacy of quinine-clindamycin combination was comparable with ACT [3].

The current dosage regimens of quinine for children, elderly, and pregnant women, based on adults' regimens, may be suboptimal due to altered physiology and pharmacokinetics [4]. None of the current systematic reviews address the impact of the differences in pharmacokinetics on quinine efficacy and safety in these vulnerable populations $[5,6]$. Pharmacokinetic investigation of quinine may be required for further dosage optimization in these populations. The objective of this study is to provide a systematic review of the existing information on the dose regimens and pharmacokinetics of quinine in children, pregnant women, and elderly populations, and to determine whether modification of dosage regimens in these populations is required.

\section{Methods}

\section{Data sources}

The Web of Science, Cochrane Library, Scopus, and PubMed were used by two independent researchers as search databases up to October 2020. The search terms included 'Quinine' AND 'Pharmacokinetics' AND 'Pregnancy' OR 'children' OR 'Pediatrics' OR 'Neonates' OR 'Newborns' OR 'Infants' OR 'Geriatrics' OR 'elderly' (> 65 years).

\section{Inclusion and exclusion criteria}

The inclusion criteria were: the article published in English, and the article involved clinical pharmacokinetic research on quinine in either children, elderly, or pregnant women.

\section{Data extraction and quality assessment}

TS and PK independently retrieved and reviewed articles, and any argument or inconsistency was resolved by the third person $(\mathrm{KN})$. The information extracted were: area under the plasma drug concentration-time curve (AUC), maximum plasma concentration $\left(C_{\max }\right)$, time to reach maximum plasma concentration $\left(t_{\max }\right)$, trough plasma concentration $\left(C_{\text {trough }}\right)$, elimination or terminal half-life $\left(t_{1 / 2}\right.$ or $\left.t_{1 / 2 \beta}\right)$, apparent volume of distribution $\left(\mathrm{V}_{\mathrm{d}}, \mathrm{V}_{\mathrm{d}} / \mathrm{F}, \mathrm{V}_{\mathrm{ss}}\right.$, or $\left.\mathrm{V}_{\mathrm{ss}} / \mathrm{F}\right)$, total clearance (CL or CL/F), efficacy, and toxicity parameters. The AUC, $\mathrm{C}_{\text {max }}$, and $\mathrm{C}_{\text {trough }}$ were normalized with body weight. As there are different values of half-life, volume of distribution, and clearance parameters reported in various studies, the full descriptions of parameter terms are used in the articles. Qualitative data are presented as number and percentage (\%). Quantitative data are summarized as mean, mean \pm SD, median, median (range), or range values. The volume of distribution and clearance for the intramuscular (im), intrarectal (ir), and oral (po) doses are reported by adjusting to an absolute bioavailability $(\mathrm{F})$ of $0.95,0.60$, and 0.76 , respectively.

Quality of the article selection process was assessed using the checklist for the assessment of the methodological quality for both randomized and non-randomized studies of health care intervention [7].

\section{Results and discussion}

Three hundred and seventy articles were retrieved from the databases, and 28 articles were selected for further analysis based on the predefined criteria (Fig. 1). The average scores for quality assessment were acceptable. Nineteen, 7, and 2 articles involved studies in children [8-26], pregnant women [27-33], and elderly [34, 35], respectively. The studies were conducted during 19822013 in 16 countries; 23, 2, and 3 studies in Africa, Asia, and Australia/Oceania, respectively. Fourteen, 11, and 3 studies involved uncomplicated falciparum malaria [8$16,27-31]$, complicated falciparum malaria [17-25, 32, $33]$, and non-malaria $[9,11,14]$, respectively.

Three pharmacokinetic analysis approaches were applied i.e., non-compartmental analysis $(\mathrm{NCA}, \mathrm{n}=13$ ) [10, 16-19, 22, 26-28, 30-32, 34], compartmentalanalysis $(C A, n=11)[8,9,11-13,15,20,21,23,33,35]$, and population-based pharmacokinetic analysis (pop$\mathrm{PK}, \mathrm{n}=4)[14,24,25,29]$. NCA is the standard method which provides pharmacokinetic parameters directly 


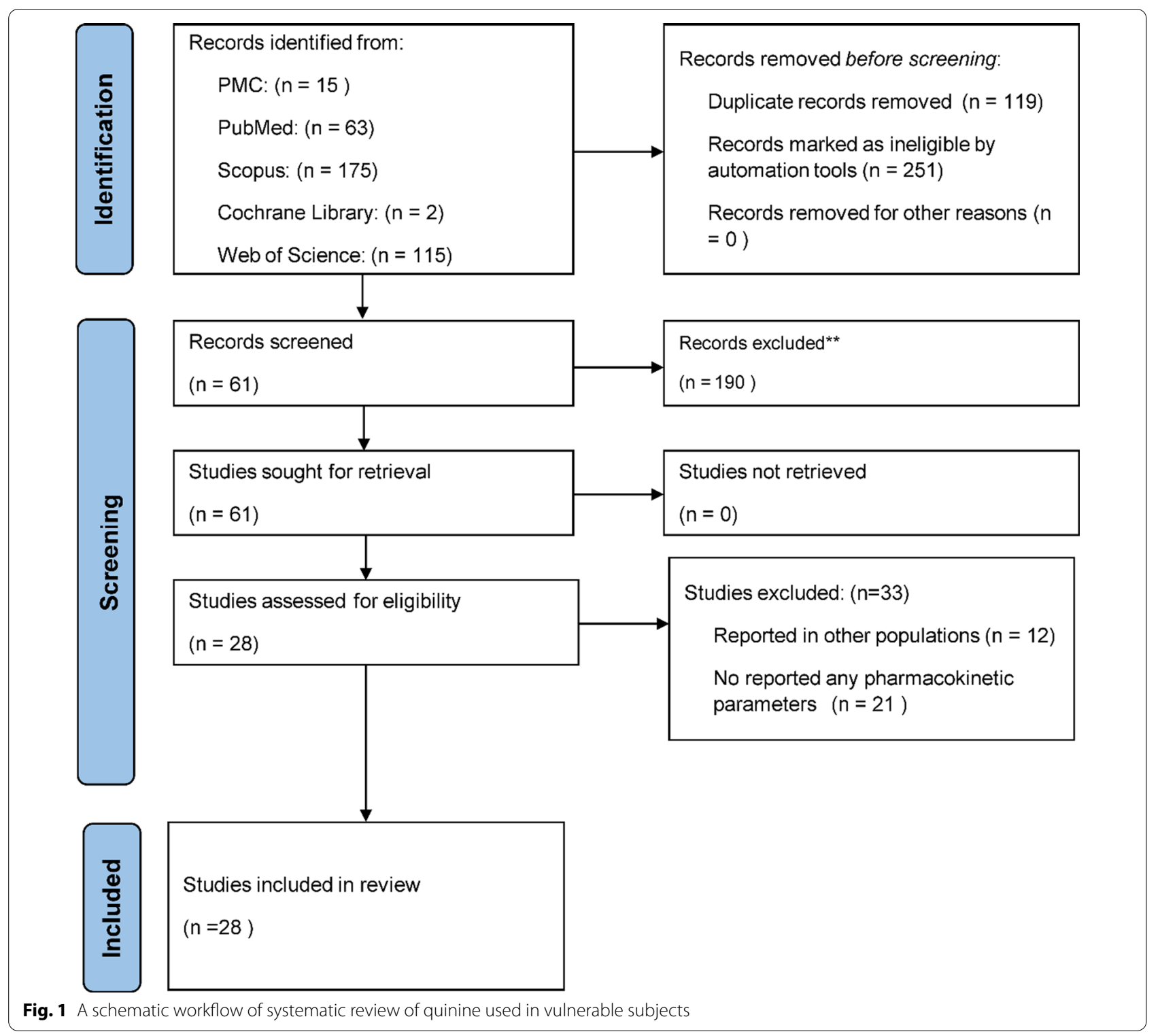

from the observed data giving a gross approximation as the result, and is not the most accurate method for parameter estimation. This analysis approach however, is not suitable for the characterization of pharmacokinetic variability in the populations. CA offers the advantage of allowing for the use of data modeling and simulation for dosage optimization. The pop-PK approach is most applicable to analysis of drug pharmacokinetics in various populations considering both intra- and inter-individual variability. Additional file 1: Table S1-3 summarizes quinine pharmacokinetics (focusing on $\mathrm{C}_{\max }$ and systemic exposure) reported in children, pregnant women, and elderly with uncomplicated and complicated malaria.

\section{Dose-dependent pharmacokinetics}

Three out of 28 articles (10.71\%) reported the pharmacokinetic parameters of both quinine and the active metabolite 3 -hydroxyquinine ( 2 and 1 in pregnancy and children, respectively) $[10,27,28]$. For quinine, the AUC, $\mathrm{C}_{\max }$, and $\mathrm{C}_{\text {trough }}$ were reported in 20 (71.4\%) [8$13,17-29,31,34], 26(82.1 \%)[8-13,15-23,25-29,31-$ $35]$, and $16(57.1 \%)$ [8-13, 15-17, 19, 21, 23, 26, 29-31] articles, respectively. The corresponding numbers for 3 -hydroxyquinine were 2 (66.7\%), 3 (100\%), and 1 (33.3\%) article(s), respectively. Since the anti-malarial potency of 3-hydroxyquinine is tenfold lower than quinine [36], measurement of plasma concentrations and analysis of pharmacokinetic parameters may be unnecessary. 


\section{Children}

$\mathrm{AUC}_{0-8 \mathrm{~h}}(\mathrm{mg} / \mathrm{l} / \mathrm{h})$ data were reported in 7 articles following different routes and dosage regimens; 5 in uncomplicated and 2 in complicated malaria ( 1 in malnourished children). The ranges of body-weight adjusted $\mathrm{AUC}_{0-8 \mathrm{~h}}$ in uncomplicated and complicated malaria were $0.97-2.47$ [8-13] and 3.10-3.74 [17-23, 25] $\mathrm{mg} / \mathrm{l} / \mathrm{h} / \mathrm{kg}$, respectively.

Malaria severity, nutritional status, administration route, and body weight are the key factors influencing quinine exposure and treatment outcomes. With iv dose administration, $\mathrm{AUC}_{0-8 \mathrm{~h}}$ following $4.74 \mathrm{mg}$ base/ $\mathrm{kg}$ in uncomplicated and complicated malaria were 1.2$2.47[8,9,13]$ and $3.1-3.7423 \mathrm{mg} / \mathrm{l} / \mathrm{h} / \mathrm{kg}$, respectively. The impact of malaria severity on quinine exposure is explained by the significantly lower rate of clearance in cases of complicated malaria $(0.06 \pm 0.04 \mathrm{l} / \mathrm{h} / \mathrm{kg})$ [1820, 23-25] compared with uncomplicated (0.09 l/h/ $\mathrm{kg})$ malaria [14] and healthy subjects $(0.24 \pm 0.14)$ [23]. Down-regulation of the drug-metabolizing enzyme cytochrome P450 (CYP) has been reported in Plasmodium chabaudi-infected mice [37]. Kwashiorkor [26], but not malnutrition [10,23], had a significant effect on quinine exposure. With equivalent dosage, the $\mathrm{AUC}_{0-8 \mathrm{~h}}$ following the im and ir routes were contradictory, being either higher [8,9] or comparable [17-20] with the iv route. The ir route provided the lowest $\mathrm{AUC}_{0-8 \mathrm{~h}}$ [23], and a threefold increase in quinine dose (base) [11] may be required to obtain an $\mathrm{AUC}_{0-8 \mathrm{~h}}$ comparable to the iv route [8]. The $\mathrm{AUC}_{0-8 \mathrm{~h}}$ following both the im and iv, but not ir route, increased linearly with dosage.

Following 7-16 $\mathrm{mg}$ base $/ \mathrm{kg}$, the $\mathrm{C}_{\max }$ in complicated malaria $(0.4-1.22 \mu \mathrm{g} / \mathrm{ml} / \mathrm{kg})[8-13,15,16]$, was relatively higher than in uncomplicated malaria $(0.34-0.95 \mu \mathrm{g} / \mathrm{ml} /$ $\mathrm{kg}$ ) [17-23, 25]. Following $4.74 \mathrm{mg}$ base $/ \mathrm{kg}$, the iv route provided the highest $C_{\max }$ (iv: $0.36 \pm 0.07$; im: $0.25 \pm 0.11$; ir: $0.17 \pm 0.11 \mu \mathrm{g} / \mathrm{l} / \mathrm{kg})[8,11]$. The mean $C_{\max }$ values in nourished and malnourished children were 0.5 and $0.67 \mu \mathrm{g} / \mathrm{ml} / \mathrm{kg}$, respectively [10]. $C_{\max }$ showed a linear relationship with dose size following ir and im administration. Simulated $\mathrm{C}_{\max }$ in children weighing $5 \mathrm{~kg}$ was $15.9 \%$ lower than those weighing $20 \mathrm{~kg}$. However, this difference was unlikely to significantly affect quinine efficacy since plasma quinine concentrations in $95 \%$ of the patients remained within the therapeutic range [25].

\section{Pregnant women}

AUC data was reported in pregnancy with uncomplicated malaria in only 4 articles [27-29, 31]. A comparison of quinine pharmacokinetics between pregnant and non-pregnant women was reported in 2 articles [27, 28] wherein the $\mathrm{AUC}_{0 \text {-inf }}$ for both groups were comparable $(8.24 \pm 2.43$ vs. $9.90 \pm 2.50 \mu \mathrm{mol} / \mathrm{l} / \mathrm{h})$ [27]. Physiological changes during pregnancy and estimated gestational age
(EGA) did not appear to significantly affect quinine exposure [29]. It is noted, however, that the number of participants in each group (7 non-pregnant and 16 pregnant women) is small and may not provide adequate statistical power to allow for an accurate conclusion on the effect of pregnancy on quinine pharmacokinetics.

$\mathrm{C}_{\max }$ was reported in all articles, 5 and 2 articles in uncomplicated and complicated malaria, respectively $(0.07-0.22$ vs. $0.19 \mu \mathrm{g} / \mathrm{ml} / \mathrm{kg})[27-29,31]$. Malaria infection and routes of administration, but not pregnancy status, had significant influence on quinine $C_{\max }$ [27]. The $\mathrm{C}_{\max }$ following iv and po routes were $0.20 \pm 0.028[27,28]$ and $0.09 \pm 0.026[29,31] \mu \mathrm{g} / \mathrm{ml} / \mathrm{kg}$, respectively.

\section{Elderly}

A study in healthy elderly following a single oral dose of $600 \mathrm{mg}$ quinine salt (497 mg base) [34] showed a significantly higher AUC in elderly compared with adults $(1.58 \pm 0.39$ vs. $1.20 \pm 0.32 \mu \mathrm{g} / \mathrm{ml} / \mathrm{kg})$, while the $C_{\max }$ values were comparable [34].

\section{Dose-independent pharmacokinetics Children}

Quinine clearance was reported in 8 studies (po, iv, and im), 2 in uncomplicated $[10,14]$, and 6 in complicated [19, 20, 23-25] malaria. Malaria infection and body weight influenced quinine clearance in children [25]. The clearance in healthy subjects and uncomplicated malaria was significantly higher than complicated malaria $(0.24 \pm 0.13$ vs. $0.15(0.08-0.25)$ vs. $0.06(0.029-0.08) \mathrm{l} / \mathrm{h} /$ $\mathrm{kg})[10,14,19,20,23-25]$. The effect of nutritional status on quinine clearance is contradictory and needs further investigation. The clearance in malnourished children with complicated malaria was slightly higher than in nourished children $(0.08 \pm 0.04$ vs. $0.07 \pm 0.04 \mathrm{l} / \mathrm{h} / \mathrm{kg})$ [23]. In uncomplicated malaria, the clearance in malnourished children was significantly higher than in nourished children $(0.25 \pm 0.20$ vs. $0.13 \pm 0.08 \mathrm{l} / \mathrm{h} / \mathrm{kg})$ [10]. Plasma protein levels (albumin, alpha1-acid glycoprotein, or AAG) and protein-binding in both groups were similar [10]. The higher clearance observed in malnourished children with uncomplicated malaria may be due to changes in drug-metabolizing enzyme activity rather than plasma protein binding. Route of administration had no effect on total quinine clearance $(0.03-0.07[19,20,23]$ and $0.035-$ $0.07[18,24,25] \mathrm{l} / \mathrm{h} / \mathrm{kg}$ for iv and im routes, respectively). There was no linear relationship between quinine clearance and malaria parasite density [17].

The volume of distribution of quinine was reported in 8 articles, 6 in complicated [17, 19, 20, 23-25] and 2 in uncomplicated malaria [10, 14] $(0.53-1.5$ vs. $1.4-2.0 \mathrm{l} /$ $\mathrm{kg})$. Body weight was a significant covariate for the volume of distribution [25]. The effect of malaria disease 
severity on volume of distribution was contradictory. The volume of distribution in cerebral malaria reported by Pussard et al. [23] was threefold lower than that reported by Frank et al. [17] $(0.53 \pm 0.1$ vs. $1.44 \pm 0.01 \mathrm{l} / \mathrm{kg}$, respectively), but was similar to adult patients with cerebral malaria $(0.74 \pm 0.30 \mathrm{l} / \mathrm{kg})$ [38]. The decrease in the volume of distribution with increasing malaria severity could be due to an increase in AAG and dehydration in patients, and/or a decrease in tissue blood flow in complicated malaria. Nutritional status had less contribution (Vd: $0.58 \pm 0.22$ vs. $0.53 \pm 0.1 \mathrm{l} / \mathrm{kg}$ for malnourished vs. nourished children with malaria) [23].

Three out of 19 studies reported models with covariates $[14,24,25]$. None provided the stratification of age along with pharmacokinetic analysis. Age (range: 6 months to 6.7 years) was not a significant covariate that influenced clearance and/or volume of distribution. Since the activities and expressions of UDP-glucuronosyltransferase 1A1 (UGT1A1) and cytochrome P450 3A4 (CYP3A4), both major quinine metabolizing enzymes, are likely to be steady in individuals aged over 6 months [39], and 24 months [40], respectively, age is unlikely to be a significant covariate. In contrast, body-weight was a significant covariate that influenced both clearance and volume of distribution. It was clear that quinine dosage should be administered based on body-weight rather than age.

The half-life values of quinine reported in healthy, uncomplicated, and complicated malaria were $6.1 \pm 1.5$ $[23], 7.2 \pm 3.3[9,11,14]$, and $11.6 \pm 4.6[17,19-21,24,25]$ $\mathrm{h}$, respectively. The half-life in complicated malaria was $16.8 \pm 3.1 \mathrm{~h}[18,20,24]$. It is noted that quinine half-life is prolonged in direct proportion to severity of infection. Additionally, its half-life is also influenced by nutritional status (malnutrition and kwashiorkor) [23, 26].

Quinine $t_{\max }$ in uncomplicated and complicated malaria ranged from 1.7 to $4.0 \mathrm{~h}[8-11,13]$ and 1.1 to $4 \mathrm{~h}$ [18-21], respectively. The im route provided the shortest $\mathrm{t}_{\max }$ (iv: $2.7-4.7[8,9,11-13,17,19,20,23]$ vs. im: 1.0-2.7 [8-10, 13, 17-19, 21] vs. ir: 1.7-4.8 [8, 9, 11-13, $21]$ vs. po: $1.5-3[14,15] \mathrm{h})$. The delayed $t_{\max }$ seen in malnourished children compared with nourished children $(6.3 \pm 1.8$ vs. $2.3 \pm 2.9$ h) [23], similar to that found with chloroquine, could be due to intestinal malabsorption [41].

\section{Pregnant women}

Quinine clearance during pregnancy was reported in 2 articles in uncomplicated [29-31] and 1 article in complicated [33] malaria $(0.11 \pm 0.04$ vs. $0.07 \mathrm{l} / \mathrm{h} / \mathrm{kg})$. Based on pop-pK analysis, the presence of an effect from EGA status on quinine clearance was unlikely, despite the positive correlation between the EGA associated-pregnancy period and quinine clearance [29]. Since CYP3A4 activity consistently increases throughout gestation, it may not have a sizeable enough impact to be a considered a covariate. Furthermore, the initial body temperature was a significant covariate that influenced clearance due to an increase in hepatic enzyme activity. In patients presenting high body temperature upon admission, plasma concentration of quinine should be monitored. Quinine volume of distribution was reported in 3 articles, 2 in uncomplicated $[29,31]$ and 1 in complicated malaria [33] $(2.4 \pm 1.3$ vs. $0.96 \pm 0.27 \mathrm{l} / \mathrm{kg}$ ). The reported volume of distribution was inconsistent. The volume of distribution values in uncomplicated malaria, based on pop-PK analysis, during the second and third-trimesters were 3.05 (2.66-4.26) and $3.05(2.75-3.86) \mathrm{l} / \mathrm{kg}$ [29], respectively. The volume of distribution estimated based on NCA in pregnant women with uncomplicated malaria was 1.1 (0.62-1.97) $1 / \mathrm{kg}$ [31], which was comparable to adult patients with uncomplicated malaria $(1.26 \pm 0.26 \mathrm{l} / \mathrm{kg})$ [42]. The demographic data (e.g., age, body-weight, gestation age, and trimester of pregnancy) of the patients from the two studies were not different $[29,31]$. However, it is clear that plasma volume in pregnancy during the first, second, and third trimesters increases up to $106 \%, 129 \%$, and $149 \%$ of that reported in non-pregnant women [43]. In addition, an increase in fat composition, extracellular fluid, and total body water during pregnancy may result in an increased volume of distribution as quinine is moderately lipophilic. The reported volume of distribution based on NCA analysis is likely to be inaccurate.

Quinine half-life was reported in 3 articles, 2 in uncomplicated [27-29,31] and 1 in complicated [33] $(9.8-16.1$ vs. $11.2+4.3 \mathrm{~h})$ malaria. Malaria severity was unlikely to affect quinine half-life during pregnancy [28]. The half-life seen in pregnant women with uncomplicated malaria, complicated malaria, and during convalescence were $12.7 \pm 2.1$ [28, 29, 31], $11.2 \pm 4.3$ [33], and $11.9 \pm 1.3 \mathrm{~h}$ [28], respectively. These results are in agreement with that reported in non-pregnant adults with cerebral malaria, uncomplicated malaria, and during convalescence $(18.2 \pm 9.7$ vs. $11 \pm 4.1$ vs. $16.0 \pm 7 \mathrm{~h}$ ) [42]. It is noted that the estimation of quinine half-life in pregnant women may be inaccurate due to the limited number of studies reporting this data.

Physiological changes during both pregnancy and malaria infection are unlikely to have affected quinine $t_{\max }$. The $t_{\max }$ was reported only in uncomplicated malaria in 3 articles, i.e., pregnant $[27-29,31]$ and nonpregnant $[27,28]$ women with uncomplicated malaria [2 (1.8-3) vs. $2.3(2-2.5) \mathrm{h}$ ], which was similar to that of the convalescent phase [2 (2-4) h] [28]. 


\section{Elderly}

Quinine clearance was reported in elderly subjects [34] and elderly diabetic patients [35]. The elderly [age: 70 (65-78) y] had a reduced clearance compared with young adults [24 (20-35) y] $(0.045 \pm 0.007$ vs. $0.06 \pm 0.02 \mathrm{l} / \mathrm{h} /$ $\mathrm{kg}$, respectively), but with comparable renal clearance $(0.01 \pm 0.003$ vs. $0.012 \pm 0.005 \mathrm{l} / \mathrm{h} / \mathrm{kg}$, respectively) [34]. Since renal clearance of quinine makes up about $20 \%$ of total clearance, the reduction of glomerular filtration rate (GFR) with age is unlikely to affect quinine clearance [44]. The diabetic status had no effect on quinine clearance $(0.049 \pm 0.42$ vs. $0.05 \pm 0.02 \mathrm{l} / \mathrm{h} / \mathrm{kg}$ for diabetic vs. non-diabetic subjects) [35].

There was no effect of diabetic status on quinine volume of distribution $(1.29 \pm 0.42$ vs. $1.29 \pm 0.45 \mathrm{l} / \mathrm{kg}$ for non-diabetic vs. diabetic subjects) [35]. The volume of distribution in the elderly was lower than adults [44], due mainly to a decrease in total body water and cardiac output.

The prolongation of quinine half-life in the elderly compared with young adults (19.2 \pm 1.1 vs. $10.5 \pm 1.6 \mathrm{~h})$ was consistent with the decrease of quinine clearance [34].

Quinine $\mathrm{t}_{\max }$ was unaffected by age $(2.3 \pm 1.2$ vs. $2.5 \pm 0.7 \mathrm{~h}$ in elderly vs. young adults) [34], which was at least in part explained by the unchanged gastric emptying rate in the elderly. It is noted that the reports of the gastric emptying rate change in elderly, reported as either delayed [45] or unchanged [46], are discordant. Demographic data (i.e., body-weight, height, body-mass index (BMI), sex, hypertensive status, and glycosylated haemoglobin level) were not evaluated as model covariates.

\section{Ethnicity}

Ethnicity can influence quinine clearance due to associated polymorphisms in drug-metabolizing enzymes. Twenty-three studies were carried out in Africans; the other 5 studies were carried out in Cambodians, New Zealanders, and Australian. There were no clinical studies that reported across different ethnic groups on the same malaria severity and vulnerable populations. The conclusion of the influence of ethnicity on quinine exposure is, therefore, limited. However, the distribution of genetic polymorphisms, including those in genes coding for drug-metabolizing enzymes, varies with ethnicity, suggesting the possibility that ethnicity could influence quinine clearance. The allele frequencies of CYP3A4*3, CYP3A4*13, CYP3A4*18, and CYP3A4*19 were 0.021 in European-Americans, 0.011 in Han-Chinese, 0.01 in Japanese, and 0 in Africans [47]. The proportions of patients with impaired quinine clearance in individuals with either CYP3A4*3, CYP3A4*13, CYP3A4*18, or CYP3A4*19 and those with the wild-type genotype CYP3A $4 * 1 \mathrm{~A}$ were $22.6 \%, 5.8 \%, 17.6 \%$, and $43 \%$, respectively [48]. In addition to the CYP3A4/5 polymorphisms in African subjects, four additional polymorphisms including CYP3A4*1B, CYP3A5*3, CYP3A5*6, and CYP3A5*7 were reported. The allele frequencies for CYP3A $4 * 1 \mathrm{~B}$, CYP3A $5 * 3$, CYP3A $5 * 6$, and CYP3A $5 * 7$ were $0.66-0.86$, $0.04-0.81,0.05-0.25$, and $0-0.21$, respectively [67]. All polymorphisms except CYP3A41*B are classified as poor metabolizer (PM) due to a reduction or non-detection of enzyme expression [67]. The decrease in enzyme activity and clearance may result in toxicity. However, results from a recent physiologically-based pharmacokinetic (PBPK) modelling study suggested that the effects of these genetic polymorphisms on quinine exposure and clearance were not clinically significant and dosage adjustment may not be required [49].

\section{Therapeutic relevance}

The clinical efficacy of different dosage regimens and routes of administration in uncomplicated malaria was excellent with a $100 \%$ cure rate $[8,9,11-16]$. It is noted that most articles reported 7-day [8, 9, 11-14] or 14-day $[15,16]$, but not 42 -day, cure rates as recommended by the World Health Organization (WHO) for the evaluation of clinical efficacy of drugs for $P$. falciparum treatment. Three out of the 9 articles reported $100 \%$ cure rates in complicated malaria [20, 21, 23]. Susceptibility of $P$. falciparum to quinine has been decreasing over time [50-55]. Quinine plasma concentrations should be maintained above the minimum inhibitory concentration (MIC) throughout the 7-day treatment period to completely eliminate the malaria parasite. In 1983, the reported MIC in children with uncomplicated malaria in Africa was $0.37 \mu \mathrm{mol} / \mathrm{l}(0.12 \mu \mathrm{g} / \mathrm{ml})$ [50], but by 1988 it had increased to $0.8(0.16-5.12) \mu \mathrm{mol} / \mathrm{l}(0.26(0.05-1.66)$ $\mu \mathrm{g} / \mathrm{ml}$ ) [51]. During the same period, the MIC reported in $P$. falciparum isolates in Thailand (Thai-Cambodian border) was $3.04 \mu \mathrm{mol} / \mathrm{l}(0.98 \mu \mathrm{g} / \mathrm{ml})$ [52]. Quinine $\mathrm{IC}_{50}$ (concentration that inhibits parasite growth by $50 \%$ ) values in adults with uncomplicated malaria in Western and Eastern Cambodia gradually increased from 2001 to 2007 (Additional file 1: Table S4) [53]. During the same period, the $\mathrm{IC}_{50}$ reported at the Thai-Myanmar and Thai-Cambodia borders had markedly increased (Additional file 1: Table S4) [54]. Besides the $\mathrm{IC}_{50}$ and MIC, mean cut-off concentration of schizont maturation (MCOC equivalent to MIC) of quinine reported in 2009 in adult patients with uncomplicated malaria in Northwestern Thailand was $36.5 \mu \mathrm{mol} / \mathrm{l}(11.84 \mu \mathrm{g} / \mathrm{ml})$ [55].

\section{Children}

Sixteen out of 19 articles reported clinical efficacy of quinine, 8 each in uncomplicated and complicated malaria. 
Quinine doses in a 3-day or 5-day regimen for uncomplicated malaria during the period of 1993-2005 varied from 4.74 to $11.85 \mathrm{mg}$ base $/ \mathrm{kg}[8,9,11-14]$. Since 2008, the recommended dose has been replaced with $8 \mathrm{mg}$ base $/ \mathrm{kg}$ (q8h) with a 7-day treatment course $[15,16]$. During 1993-2002, the FCT (fever clearance time) following a dosage of $4.74-11.85 \mathrm{mg}$ base $/ \mathrm{kg}$ was within $36 \mathrm{~h}[8,9,11,12]$, but has been prolonged up to $72 \mathrm{~h}$ since 2004 [13]. With the same dosage regimen, the FCT following the iv was faster than ir route (48 vs. $72 \mathrm{~h}$ ) [13]. The reported influence of dose on FCT was inconsistent between reports, being either comparable for all doses (within $36 \mathrm{~h}$ ) [11], or shortening as dose increased [13]. An increase in dose could reduce FCT due to faster parasite killing (dose response curve). The PCT (parasite clearance time) reported in uncomplicated malaria following 4.74-11.85 $\mathrm{mg}$ base/ $\mathrm{kg}$ was 48-96 h [8, 9, 11-16]. The PCT was shorter following iv administration compared with the ir route (48 vs.72 h) [12]. Two articles however, reported similar PCT data with different routes (iv, im, and ir) and dosage regimens [8, 13]. Notably, other contributing factors, e.g., initial parasitemia and body-weight, were not taken into consideration during the analysis, which could be unaddressed confounding factors that resulted in incorrect data interpretation $[8$, 13].

Quinine doses used in complicated malaria treatment varied from 4.74 to $16.35 \mathrm{mg}$ base $/ \mathrm{kg}$ (with or without a loading dose). Four out of 8 articles reported both FCT $[19,21-23]$ and PCT $[19,21,22,24]$. The FCT and PCT values in complicated malaria were 25.1-48.6 and 27.4-49.5 h, respectively [19, 21-23]. The FCT following im administration $[19,22]$ was shorter than the ir [21] route $(27.4 \pm 3.6$ vs. $48.6 \pm 2.7 \mathrm{~h})$. This was in agreement with the relatively short $t_{\max }$ following im administration compared with ir routes. Time to regain consciousness was 36-39 h [19]. A recent systematic review and metaanalysis however, concluded no significant difference in PCT, FCT, mortality rate, duration of hospitalization, and time-to-drinking between IR and IM administration [56], but not for the effect of dosage.

Fifteen out of the 19 articles reported $\mathrm{C}_{\text {trough }}$ at different time points, 8 articles in uncomplicated [8-13, $15,16]$ and 6 articles in complicated $[17-19,21,23,25]$ malaria, and 1 article in kwashiorkor [26]. Therapeutic ranges of total quinine concentration for children with complicated and uncomplicated malaria in Africa before and during 1994 ranged from 0.2 to $2.0 \mu \mathrm{g} /$ $\mathrm{ml}$ [57], and $0.21-0.35 \mu \mathrm{g} / \mathrm{ml}$ unbound quinine [11], respectively. Despite the continuous decline in sensitivity of $P$. falciparum to quinine over time, the current analysis suggests that total $C_{\text {trough }}$ in most studies in both complicated and uncomplicated malaria were maintained above the MIC for 7 days with a clinical efficacy of $100 \%$. Total quinine $\mathrm{C}_{\text {trough }}$ during $1983-$ 2010 in uncomplicated malaria ranged from 1.42 to $10.43 \mu \mathrm{g} / \mathrm{ml}(0.1-0.73 \mu \mathrm{g} / \mathrm{ml}$ free quinine) $[8,9,11-$ $13,15,16]$. Results of pharmacokinetic/pharmacodynamic modeling reported in 2003 suggested a total $\mathrm{C}_{\text {trough }}$ of at least $3.4 \mu \mathrm{g} / \mathrm{ml}(0.34 \mu \mathrm{g} / \mathrm{ml}$ free quinine, $\mathrm{f}_{\mathrm{u}}=0.109$ [58]) for curative treatment of uncomplicated falciparum malaria in Thai adults [59]. The consensus meeting in 2007 concluded that the required $\mathrm{C}_{\text {trough }}$ for uncomplicated malaria was $10-12 \mu \mathrm{g} /$ $\mathrm{ml} 1(1.09-1.31 \mu \mathrm{g} / \mathrm{ml}$ free quinine) [60], which is equivalent to $9.5-11.50 \mu \mathrm{g} / \mathrm{ml}$ total $\mathrm{C}_{\text {trough }}$ in children $\left(f_{u}=0.114,1.08-1.3 \mu \mathrm{g} / \mathrm{ml}\right.$ free concentrations) [14]. The therapeutic $\mathrm{C}_{\text {trough }}$ of quinine in children with uncomplicated malaria is therefore, $9.5-11.50 \mu \mathrm{g} / \mathrm{ml}$. The dosage regimens that provided the required total $\mathrm{C}_{\text {trough }}$ in children with uncomplicated malaria were a 7-day course of multiple doses of 8 [16] or 10-12 [15] $\mathrm{mg}$ base/kg q8h for iv administration and $12 \mathrm{~h}$ for im administration. In addition, the suggested ir regimen was multiple doses of $11.84 \mathrm{mg}$ base $/ \mathrm{kg}$ q8h. Such routes and dose frequency of quinine administration also contribute to quinine exposure and therapeutic outcome. Dosage adjustment in children with uncomplicated malaria may not be required [Table 1], which is applicable for quinine use in malaria endemic areas where quinine sensitivity is still sufficient. In addition to improved patient compliance, im administration appears most preferable due to its lower frequency of drug administration [Table 1].

For complicated malaria, the therapeutic range of quinine for adults reported in 1983 was $5-10 \mu \mathrm{g} / \mathrm{ml}$ $(0.35-0.7 \mu \mathrm{g} / \mathrm{ml}$ free quinine) [61] or $10-15 \mu \mathrm{g} / \mathrm{ml}$ $\left(0.7-1.05 \mu \mathrm{g} / \mathrm{ml}\right.$ unbound quinine) [62]. Quinine $\mathrm{C}_{\text {trough }}$ during 1982-2010 in complicated malaria ranged from 2.7 to $12 \mu \mathrm{g} / \mathrm{ml}(0.15-0.66 \mu \mathrm{g} / \mathrm{ml}$ free quinine) [17-19, $21,23,25]$. The predicted $C_{\text {trough }}$ based on data analysis from uncomplicated malaria during 1948-1995 was $8-15 \mu \mathrm{g} / \mathrm{ml}(0.72-1.05 \mu \mathrm{g} / \mathrm{ml}$ unbound quinine) for curative treatment of complicated malaria [25]. The suggested therapeutic $\mathrm{C}_{\text {trough }}$ in children with complicated malaria is therefore $14.4-19.09 \mu \mathrm{g} / \mathrm{ml}\left(f_{\mathrm{u}}=0.055\right.$ [20], $0.72-1.05 \mu \mathrm{g} / \mathrm{ml}$ free quinine). None of the dosage regimens reported in the current analysis provided sufficient $\mathrm{C}_{\text {trough }}$ for treatment of complicated malaria in children [Table 1]. It is noted that the recommended standard dose regimen for complicated malaria was not used in the included articles. Pharmacokinetic/pharmacodynamic studies of quinine in children with complicated malaria following standard dose regimens are required to evaluate their effectiveness. 
Table 1 A summary of promising quinine dose regimens used in clinical studies during 1982 to 2013 in vulnerable subjects

\begin{tabular}{|c|c|c|c|}
\hline \multirow[t]{2}{*}{ Population } & \multirow[t]{2}{*}{ Dose regimen } & \multicolumn{2}{|c|}{ Required dose adjustment } \\
\hline & & $\begin{array}{l}\text { Uncomplicated } \\
\text { malaria }\end{array}$ & $\begin{array}{l}\text { Complicated } \\
\text { malaria }\end{array}$ \\
\hline Children & $\begin{array}{l}8-12 \mathrm{mg} \text { base/kg iv q8h for } 7 \mathrm{~d} \\
8-12 \mathrm{mg} \text { base/kg im q12h for } 7 \mathrm{~d}\end{array}$ & $\mathrm{~N}$ & $Y^{*}$ \\
\hline Pregnant women & $\begin{array}{l}8.3 \mathrm{mg} \text { base } / \mathrm{kg} \text { PO q8h for } 7 \mathrm{~d} \\
\text { Loading dose of } 16.7 \mathrm{mg} \text { base } / \mathrm{kg} \text { iv over } 4 \mathrm{~h} \text {, followed by } 8.3 \mathrm{mg} \text { base } / \mathrm{kg} \text { q } 8 \mathrm{~h}\end{array}$ & $\begin{array}{l}\text { Y } \\
-\end{array}$ & $\bar{Y}$ \\
\hline Elderly & $\begin{array}{l}8.3 \mathrm{mg} \text { base } / \mathrm{kg} \text { PO q8h for } 7 \mathrm{~d} \\
\text { Loading dose of } 16.7 \mathrm{mg} \text { base } / \mathrm{kg} \text { iv over } 4 \mathrm{~h} \text {, followed by } 8.3 \mathrm{mg} / \mathrm{kg} \text { q } 8 \mathrm{~h} \text { until } \\
\text { patients can swallow then complete oral dose regimen }\end{array}$ & $\begin{array}{l}\mathrm{N}^{* *} \\
\mathrm{~N}^{* *}\end{array}$ & $\begin{array}{l}\mathrm{N}^{* *} \\
\mathrm{~N}^{* *}\end{array}$ \\
\hline
\end{tabular}

Iv intravenous infusion, im intramuscular injection, $P O$ per oral

*No standard regimen of quinine administration reported for complicated malaria; **the results were estimated from a single dose of 600 mg of quinine administration in elderly

\section{Pregnant women}

Four out of 7 articles reported clinical efficacy of quinine, 3 in uncomplicated [28, 30,31] and 1 in complicated [32] malaria during pregnancy. PCT was reported in 1 study (24-57 h) [30]. None of the included studies reported FCT. The cure rates in uncomplicated and complicated malaria were $99.2 \%[28,31]$, and $91.67 \%$ [32], respectively. Two quinine regimens were used for uncomplicated malaria, i.e., multiple oral doses of $8.3 \mathrm{mg}$ base $/ \mathrm{kg}$ q8h for 7 days [29-31], and a single oral dose followed by artemether (ACT) [27]. In complicated malaria, a standard dose regimen (a loading dose of $16.7 \mathrm{mg}$ base IV over $4 \mathrm{~h}$, followed by $8.3 \mathrm{mg}$ base/kg IV over $4 \mathrm{~h}$ q8h) was applied $[32,33]$. Three articles reported $C_{\text {trough }}, 2$ in uncomplicated [29,31] and 1 in complicated [33] malaria (Additional file 1: Table S4). The required total $C_{\text {trough }}$ values for uncomplicated [60] and complicated malaria [61] in pregnant women based on the current information in adults were $13-16 \mu \mathrm{g} / \mathrm{ml}$, and $12.9-18.8 \mu \mathrm{g} / \mathrm{ml}$, respectively. The therapeutic ranges of quinine for uncomplicated and complicated malaria during pregnancy, based on a study in Thailand [42] and France [60], were 14.25717.5 [42] and $15.825-25.40 \mu \mathrm{g} / \mathrm{ml}$ [60], respectively. In addition to the curative treatment, the required total $\mathrm{C}_{\text {trough }}$ values for uncomplicated and complicated malaria during pregnancy (based on information in children [11] and adults [62]) were $2.6-4.37$ and $7-14 \mu \mathrm{g} / \mathrm{ml}$, respectively. However, total reported $C_{\text {trough }}$ values in uncomplicated and complicated malaria were 2-3.9 [29,31] and 7.1 [33] $\mu \mathrm{g} / \mathrm{ml}$, respectively (Additional file 1: Table S4). Therefore, none of the reported regimens provided adequate total quinine concentrations. Quinine dose adjustment may be required for pregnant women with uncomplicated and complicated malaria (Table 1). It is noted that the contribution of pharmacokinetics on quinine exposure remains inconclusive due to the limitation of sample size (See in Dose-dependent pharmacokinetics (Pregnant women)).

\section{Elderly}

With a single oral dose of $600 \mathrm{mg}$, plasma quinine concentration in elderly subjects was $10 \%$ lower than healthy adults [34] (Additional file 1: Table S3). There has been no pharmacokinetic study of this dose regimen in elderly with uncomplicated malaria. The $\mathrm{C}_{\text {trough }}$ in elderly, estimated from non-elderly adult patients with uncomplicated malaria $(4.5 \mu \mathrm{g} / \mathrm{ml})$ [59], is $4 \mu \mathrm{g} / \mathrm{ml}$. Quinine plasma protein binding was unaffected by age [63]. An unbound $C_{\text {trough }}$ concentration of $0.4 \mu \mathrm{g} / \mathrm{ml}$ in elderly is, thus, considered sufficient for uncomplicated malaria therapy. Plasma quinine concentration at steady-state in adult patients with severe malaria following standard regimen was $14(10-20) \mu \mathrm{g} / \mathrm{ml}$ [64], which corresponds to $12.46 \mu \mathrm{g} / \mathrm{ml}$ in elderly. This $\mathrm{C}_{\text {trough }}$ is within the therapeutic range (10-20 $\mu \mathrm{g} / \mathrm{ml})$, and quinine dose adjustment may not be necessary for elderly (Table 1 ). Clinical study is required to support this argument.

The effects of anatomical and physiological differences in children and elderly, but not pregnant women, do not appear to influence the pharmacokinetics and clinical efficacy of quinine. Standard dose regimens of quinine are likely to be sufficient for effective malaria treatment in children (uncomplicated malaria) and elderly (uncomplicated and complicated malaria). Due to the expansion of plasma volume which may result in inadequate plasma quinine exposure, dose adjustment is likely to be required in pregnant women.

\section{Quinine adverse reactions and toxicity Children}

Eight out of 19 articles reported adverse reactions after quinine dosing, 3 in uncomplicated [11-13] and 5 in complicated [18-20, 24, 25] malaria. In uncomplicated 
malaria, no adverse reactions were reported following quinine doses ranging from $8.3 \mathrm{mg}$ base (iv/im) to $11.85 \mathrm{mg}$ base (ir), which produced $\mathrm{C}_{\max }$ ranging from 4.43 to $9.86 \mu \mathrm{g} / \mathrm{ml}\left(0.31-0.69 \mu \mathrm{g} / \mathrm{ml}\right.$ unbound $\left.C_{\max }\right)$ [1113]. $A C_{\max }$ of over $20 \mu \mathrm{g} / \mathrm{ml}\left(1.4 \mu \mathrm{g} / \mathrm{ml}\right.$ free $\left.C_{\max }\right)$ was reported in adult patients with cerebral malaria without toxicity [42]. The estimated toxic concentration in children based on healthy adult information is $28 \mu \mathrm{g} / \mathrm{ml}$. The comparatively high toxic concentration reported in children was likely due to the increase in the fraction of free plasma drug in children.

Hypoglycaemia is a commonly reported adverse reaction to quinine in complicated malaria treatment $(1-15 \%)$ [18, 19, 24, 25]. One article reported no association with hypoglycaemia in children with uncomplicated malaria [19]. The other 3 reported an association, but without supportive evidence on insulin levels [18, 24, 25]. Only 1 article reported quinine $\mathrm{C}_{\max }$ of $25.9 \mu \mathrm{g} / \mathrm{ml}$ at the time of hypoglycaemia [18]. Two articles suggested that the standard glucose dose ( $3 \mathrm{mg} / \mathrm{kg} / \mathrm{min}$ or $5 \%$ dextrose iv infusion) might be insufficient to correct hypoglycaemia in children [24, 25], instead suggesting a dose of $6 \mathrm{mg} / \mathrm{kg} / \mathrm{min}$ [24]. The risk of quinine-induce hypoglycaemia is increased 3.2- (1.0-9.8) fold and should be a concern in children with pre-existing hypoglycaemia [24]. Since children with complicated malaria are likely to develop hypoglycaemia upon starting treatment, those that do present should have their blood glucose levels monitored throughout the treatment course.

QRS prolongation is one of the most serious concerns of quinine toxicity. One study reported a $10 \%$ incidence of QRS prolongation in children with complicated malaria receiving quinine treatment [20]; in this study, two patients experienced QRS prolongation leading to death, the quinine $C_{\max }$ of one of them was $16.9 \mu \mathrm{g} / \mathrm{ml}$ [20]. However, no correlation between QRS prolongation and free quinine concentration was found [20]. Although there was no correlation between QRS and free quinine concentration, plasma quinine concentration should be monitored.

Local irritation or pain at the injection site was commonly reported (12\%) following im quinine administration but these symptoms resolved within 4 weeks [24]. The incidence of transient neurologic sequelae was $5 \%(1 / 18)$ with the standard quinine regimen in severe malaria [19]; however, there was no information on plasma quinine concentrations. Quinine $\mathrm{C}_{\max }$ in fatal $(15.0 \pm 7.8 \mu \mathrm{g} / \mathrm{ml}, \mathrm{n}=2)$ and nonfatal $(15.0 \pm 3.9 \mu \mathrm{g} / \mathrm{ml}, \mathrm{n}=19)$ cases were similar, although the $\mathrm{C}_{\max }$ in one fatal case was markedly high $(25.9 \mu \mathrm{g} /$ $\mathrm{ml})$ [18]. About 5\% (4/75) of children with complicated malaria receiving quinine had plasma concentrations over $25 \mu \mathrm{g} / \mathrm{ml}$ without toxicity [25]. The safety level of plasma quinine concentration (MTC) in complicated malaria could be as high as $25 \mu \mathrm{g} / \mathrm{ml}$ due to the higher level of plasma protein binding of quinine [20].

\section{Pregnant women}

Three out of 7 articles reported adverse reactions to quinine, 1 in uncomplicated [30] and 2 in complicated [32, 33] malaria. Mild-to-moderate tinnitus, headache, and epigastric pain occurred in uncomplicated malaria patients but they had recovered within 2-7 days [30].

Hypoglycaemia was the most commonly reported $(50-100 \%)$ adverse reaction to quinine in complicated malaria [32, 33]. The relationship between plasma quinine concentrations and arterial blood pressure has been reported by Phillips et al. [33]. Quinine appears not to augment uterine contractions nor induce fetal distress.

\section{Elderly}

Adverse reactions to quinine were reported in two subjects after a single oral dose of $600 \mathrm{mg}$, one in an elderly patient with dizziness $(4 \mu \mathrm{g} / \mathrm{ml})$ and another in a young subject with tinnitus $(4.3 \mu \mathrm{g} / \mathrm{ml})$ [34]. Quinine-induced dizziness is of critical concern since it can lead to the fatal injury in the elderly [65]. Therefore, quinine dose administration in elderly, particularly by parenteral route, should be done carefully. Tinnitus was reversible without additional treatment. Since hypoglycaemia was the most commonly reported adverse reaction to quinine in other vulnerable groups, physicians should carefully prescribe quinine and advise patients of its side-effects.

\section{Pharmacokinetic analysis approaches}

The average half-life based on NCA, CA, and pop$\mathrm{PK}$ approaches in uncomplicated malaria were 10 [10], 10 [9], and 9.1 [14] h, respectively. The corresponding values in complicated malaria were $11.6 \pm 3$ [17-19], $12.0 \pm 3.8[20,21,23]$, and $16 \pm 5.5[24,25]$ $\mathrm{h}$. The volume of distribution vs. clearance reported using NCA and pop-PK in uncomplicated malaria were $1.6 \mathrm{l} / \mathrm{kg}$ vs. $1.48 \mathrm{l} / \mathrm{h} \mathrm{[10]}$ and $1.12 \mathrm{l} / \mathrm{kg}$ vs. $1.12 \mathrm{l} / \mathrm{h}$ [14], respectively. The parameters reported in complicated malaria applying NCA, CA, and pop-PK were $1.36 \pm 0.2 \mathrm{l} / \mathrm{kg}$ vs. $0.07 \pm 0.01 \mathrm{l} / \mathrm{h}[17,19], 0.80 \pm 0.35 \mathrm{l} /$ $\mathrm{kg}$ vs. $0.045 \pm 0.015 \mathrm{l} / \mathrm{h}[20,23]$, and $1.31 \pm 0.10 \mathrm{l} / \mathrm{kg}$ vs. $0.063 \pm 0.013 \mathrm{l} / \mathrm{h}[24,25]$, respectively. The half-life, volume of distribution, and clearance reported based on the three approaches in uncomplicated malaria were comparable. However, the reported half-life and volume of distribution in complicated malaria based on CA were both slightly lower than those of NCA. 


\section{Limitations and suggestions}

The MIC or MCOC of quinine for P. falciparum malaria has not been reported since 2007 [55]. As the susceptibility of $P$. falciparum to quinine changes over time, inaccurate estimation of MIC and MCOC values may lead to inappropriate dose optimization in populations. The sample sizes used in most studies are small, which may not provide adequate power to detect small differences in the parameters under investigation, and thus, lead to incorrect data interpretation and conclusions. The study designs applied in most studies are not double-blind, or randomized controlled trials (RCT), which could result in bias influencing data interpretation and conclusions. Only a few studies applied statistical analysis to draw conclusions on the significant difference between the observed parameters. The heterogeneity of blood sampling frequency for pharmacokinetic investigations makes comparison among various groups or populations difficult. A conclusive understanding of the effect of a single factor (malaria disease, pregnancy status, age) on quinine pharmacokinetics is obscured by the intertwined nature of these factors in the studied populations. Further, pregnancy status (trimester periods) and age groups are not well defined in some studies. As quinine pharmacokinetics varies as a result of the physiological differences between children, elderly, and pregnant women, data obtained from such ill-defined subpopulations could lead to misguided conclusions. Conducting large clinical trials with a sufficient number of participants may have several limitations and ethical concerns in these vulnerable groups of malaria patients. In recent years, PBPK has emerged as a promising pharmacokinetic analysis tool which could be applied for accurate dose optimization for various drug classes with no requirement of large study sample sizes. PBPK is a mathematical model describing drug disposition in the human body based on prior knowledge from both in vitro and in vivo studies [66]. This model consists of various compartments corresponding to real anatomy and physiology of humans and can accurately predict optimal drug dosage regimens in various populations using a large number of virtual populations and applying prior knowledge from past clinical studies [66] (Additional file 1)

\section{Conclusion}

The information of quinine pharmacokinetics in children, pregnant women, and the elderly with uncomplicated and complicated malaria are limited. Malaria infection and severity, routes of quinine administration, and nutritional status are the key factors that influence quinine systemic exposure and pharmacokinetics. The recommended dosages for both uncomplicated and complicated malaria are, in general, adequate for the elderly and children with uncomplicated malaria. In pregnant women with either uncomplicated or complicated malaria, and children with complicated malaria however, dose adjustment may be required. The discrepancies of the reported pharmacokinetics, particularly the volume of distribution and clearance, limit accurate dose optimization. Large clinical trials applying pop-PK or PBPK analysis would provide insight on the clinically relevant relationship between pharmacokinetics and clinical outcome parameters following various quinine dose regimens in these vulnerable populations.

\section{Key points}

Standard dose regimens of quinine for the treatment of uncomplicated and complicated malaria optimized for the general population have been used in special population (i.e., children, pregnant women, and the elderly) without adjustment, even though these special populations have differences in their physiology and anatomy. Current standard dose regimens for malaria treatment for both uncomplicated and complicated malaria are sufficient for the elderly, but not for pregnant women. In addition to children, only the standard dosage regimen of quinine for uncomplicated malaria treatment is sufficient for malaria treatment. However, no standard dosage regimen of quinine for complicated malaria has been applied in children.

\section{Supplementary Information}

The online version contains supplementary material available at https://doi. org/10.1186/s12936-022-04065-1.

Additional file 1: Table S1. Summary of quinine pharmacokinetic studies in children with malaria (uncomplicated malaria and complicated malaria). Pharmacokinetic parameters (Cmax and systemic exposure) are presented as mean + SD or mean or median (range) or median values. Table S2. Summary of quinine pharmacokinetic studies in pregnant women with malaria (uncomplicated malaria and complicated malaria). Pharmacokinetic parameters (Cmax and systemic exposure) are presented as mean + SD or mean or median (range) or median values. Table S3. Summary of quinine pharmacokinetic studies in the elderly. Pharmacokinetic parameters (Cmax and systemic exposure) are presented as mean+SD or mean or median (range) or median values. Table S4. In vitro quinine susceptibility (IC50) for Plasmodium falciparum isolates collected from Cambodia (2001-2007) and Thailand border (1998-2003).

\section{Acknowledgements}

We thank to Dr. Panida Kongjam (PK) for her contribution of article selection and Mr. Ethan Vindwamara, an American biologist, for English language edit of the manuscript. Kesara Na-Bangchang $(\mathrm{KN})$ is supported by the National Research Council of Thailand (Ministry of Higher Education, Science, Research and Innovation) under the Research Team Promotion grant (grant number NRCT 820/2563).

\section{Authors' contributions}

Study design: TS; KN. Collection and assembly of data: TS; KN; PK; Data analysis TS; KN. Data interpretation:TS; KN. Draft manuscript: TS: Manuscript review and revisions: KN. Final approval of manuscript: TS; KN. All authors read and approved the final manuscript. 


\section{Funding}

This study received funding from Thammasat University (Center of Excellence in Pharmacology and Molecular Biology of Malaria and Cholangiocarcinoma, 2019) and the National Research Council of Thailand.

\section{Availability of data and materials}

Not applicable.

\section{Code availability}

Not applicable.

\section{Declarations}

\section{Ethical approval}

This is a systematic review so there is no relevance to the experimental studies neither human nor animals.

\section{Consent to participate}

Not applicable.

\section{Consent for publication}

Not applicable.

\section{Competing interests}

Authors report no conflicts of interest. The authors alone are responsible for the content and writing of this article.

\section{Author details}

${ }^{1}$ Center of Excellence in Pharmacology and Molecular Biology of Malaria and Cholangiocarcinoma, Chulabhorn International College, Thammasat University, Rangsit Campus, 99 Moo 18 Phaholyothin Road, Klong Luang District, Pathumthani 12121, Thailand. ${ }^{2}$ Drug Discovery and Development Center, Office of Advanced Science and Technology, Thammasat University, Pathumthani, Thailand.

\section{Received: 11 August 2021 Accepted: 30 January 2022}

Published online: 10 February 2022

\section{References}

1. WHO. Guidelines for the treatment of malaria. 3rd Edn. Geneva, World Health Organization, 2015.

2. Sinclair D, Donegan S, Isba R, Lalloo DG. Artesunate versus quinine for treating severe malaria. Cochrane Database Syst Rev. 2012;2012:CD005967.

3. Saito M, Mansoor R, Kennon K, Anvikar AR, Ashley EA, Chandramohan $D$, et al. Efficacy and tolerability of artemisinin-based and quinine-based treatments for uncomplicated falciparum malaria in pregnancy: a systematic review and individual patient data meta-analysis. Lancet Infect Dis. 2020;20:943-52.

4. White NJ. Pharmacokinetic and pharmacodynamic considerations in antimalarial dose optimization. Antimicrob Agents Chemother. 2013;57:5792-807.

5. Anger GJ, Piquette-Miller M. Pharmacokinetic studies in pregnant women. Clin Pharmacol Ther. 2008;83:184-7.

6. Lu H, Rosenbaum S. Developmental pharmacokinetics in pediatric populations. J Pediatr Pharmacol Ther. 2014;19:262-76.

7. Downs SH, Black N. The feasibility of creating a checklist for the assessment of the methodological quality both of randomised and nonrandomised studies of health care interventions. J Epidemiol Community Health. 1998;52:377-84.

8. Barennes H, Pussard E, Mahaman Sani A, Clavier F, Kahiatani F, Granic G, et al. Efficacy and pharmacokinetics of a new intrarectal quinine formulation in children with Plasmodium falciparum malaria. Br J Clin Pharmacol. 1996:41:389-95.

9. Barennes H, Verdier F, Clavier F, Pussard E. Pharmacokinetics of quinimax ${ }^{\circledR}$ suppositories in children with malaria: a preliminary study. Clin Drug Investig. 1999;17:287-91.
10. Treluyer JM, Roux A, Mugnier C, Flouvat B, Lagardere B. Metabolism of quinine in children with global malnutrition. Pediatr Res. 1996;40:558-63.

11. Barennes H, Pussard E, Sani A, Clavier F, Henzel D, Kahiatani F, et al. Intrarectal Quinimax ${ }^{\circledR}$ (a combination of Cinchona alkaloids) administered at 3 different dosages to children with Plasmodium falciparum malaria in Niger. Clin Drug Investig. 1996;11:154-8.

12. Barennes H, Sterlingot H, Nagot N, Meda H, Kabore M, Sanou M, et al. Intrarectal pharmacokinetics of two formulations of quinine in children with falciparum malaria. Eur J Clin Pharmacol. 2003;58:649-52.

13. Pussard E, Straczek C, Kabore I, Bicaba A, Balima-Koussoube T, Bouree $P$, et al. Dose-dependent resorption of quinine after intrarectal administration to children with moderate Plasmodium falciparum malaria. Antimicrob Agents Chemother. 2004;48:4422-6.

14. Le Jouan M, Jullien V, Tetanye E, Tran A, Rey E, Treluyer JM, et al. Quinine pharmacokinetics and pharmacodynamics in children with malaria caused by Plasmodium falciparum. Antimicrob Agents Chemother. 2005;49:3658-62.

15. Kayumba PC, Twagirumukiza M, Huyghebaert N, Ntawukuliryayo JD, van Bortel L, Vervaet C, et al. Taste-masked quinine sulphate pellets: bio-availability in adults and steady-state plasma concentrations in children with uncomplicated Plasmodium falciparum malaria. Ann Trop Paediatr. 2008;28:103-9.

16. Kayitare E, Vervaet C, Mehuys E, Kayumba PC, Ntawukulilyayo JD, Karema C, et al. Taste-masked quinine pamoate tablets for treatment of children with uncomplicated Plasmodium falciparum malaria. Int J Pharm. 2010;392:29-34.

17. Shann F, Stace J, Edstein M. Pharmacokinetics of quinine in children. J Pediatr. 1985;106:506-10.

18. Waller D, Krishna S, Craddock C, Brewster D, Jammeh A, Kwiatkowski $D$, et al. The pharmacokinetic properties of intramuscular quinine in Gambian children with severe falciparum malaria. Trans R Soc Trop Med Hyg. 1990;84:488-91.

19. Pasvol G, Newton CR, Winstanley PA, Watkins WM, Peshu NM, Were $J B$, et al. Quinine treatment of severe falciparum malaria in African children: a randomized comparison of three regimens. Am J Trop Med Hyg. 1991;45:702-13.

20. van Hensbroek MB, Kwiatkowski D, van den Berg B, Hoek FJ, van Boxtel CJ, Kager PA. Quinine pharmacokinetics in young children with severe malaria. Am J Trop Med Hyg. 1996;54:237-42.

21. Barennes H, Kahiatani F, Pussard E, Clavier F, Meynard D, Njifountawouo S, et al. Intrarectal Quinimax (an association of Cinchona alkaloids) for the treatment of Plasmodium falciparum malaria in children in Niger: efficacy and pharmacokinetics. Trans R Soc Trop Med Hyg. 1995;89:418-21.

22. Newton CR, Winstanley PA, Watkins WM, Mwangi IN, Waruiru CM, Mberu EK, et al. A single dose of intramuscular sulfadoxinepyrimethamine as an adjunct to quinine in the treatment of severe malaria: pharmacokinetics and efficacy. Trans R Soc Trop Med Hyg. 1993;87:207-10.

23. Pussard E, Barennes H, Daouda H, Clavier F, Sani AM, Osse M, et al. Quinine disposition in globally malnourished children with cerebral malaria. Clin Pharmacol Ther. 1999;65:500-10.

24. Krishna S, Nagaraja NV, Planche T, Agbenyega T, Bedo-Addo G, Ansong D, et al. Population pharmacokinetics of intramuscular quinine in children with severe malaria. Antimicrob Agents Chemother. 2001;45:1803-9.

25. Hendriksen IC, Maiga D, Lemnge MM, Mtove G, Gesase S, Reyburn H, et al. Population pharmacokinetic and pharmacodynamic properties of intramuscular quinine in Tanzanian children with severe Falciparum malaria. Antimicrob Agents Chemother. 2013;57:775-83.

26. Salako LA, Sowunmi A, Akinbami FO. Pharmacokinetics of quinine in African children suffering from kwashiorkor. Br J Clin Pharmacol. 1989;28:197-201.

27. Abdelrahim II, Adam I, Elghazali G, Gustafsson LL, Elbashir MI, Mirghani RA. Pharmacokinetics of quinine and its metabolites in pregnant Sudanese women with uncomplicated Plasmodium falciparum malaria. J Clin Pharm Ther. 2007;32:15-9.

28. Mirghani RA, Elagib I, Elghazali G, Hellgren U, Gustafsson LL. Effects of Plasmodium falciparum infection on the pharmacokinetics of quinine and its metabolites in pregnant and non-pregnant Sudanese women. Eur J Clin Pharmacol. 2010;66:1229-34. 
29. Kloprogge F, Jullien V, Piola P, Dhorda M, Muwanga S, Nosten F, et al. Population pharmacokinetics of quinine in pregnant women with uncomplicated Plasmodium falciparum malaria in Uganda. J Antimicrob Chemother. 2014;69:3033-40.

30. Kayentao K, Guirou EA, Doumbo OK, Venkatesan M, Plowe CV, Parsons TL, et al. Preliminary study of quinine pharmacokinetics in pregnant women with malaria-HIV co-infection. Am J Trop Med Hyg. 2014;90:530-4.

31. Tarning J, Kloprogge F, Dhorda M, Jullien V, Nosten F, White NJ, et al. Pharmacokinetic properties of artemether, dihydroartemisinin, lumefantrine, and quinine in pregnant women with uncomplicated Plasmodium falciparum malaria in Uganda. Antimicrob Agents Chemother. 2013;57:5096-103.

32. Looareesuwan S, Phillips RE, White NJ, Kietinun S, Karbwang J, Rackow $C$, et al. Quinine and severe falciparum malaria in late pregnancy. Lancet. 1985;2:4-8.

33. Phillips RE, Looareesuwan S, White NJ, Silamut K, Kietinun S, Warrell DA. Quinine pharmacokinetics and toxicity in pregnant and lactating women with falciparum malaria. Br J Clin Pharmacol. 1986;21:677-83.

34. Wanwimolruk S, Chalcroft S, Coville PF, Campbell AJ. Pharmacokinetics of quinine in young and elderly subjects. Trans R Soc Trop Med Hyg. 1991;85:714-7.

35. Dyer JR, Davies TM, Giele C, Annus T, Garcia-Webb P, Robson J. The pharmacokinetics and pharmacodynamics of quinine in the diabetic and non-diabetic elderly. Br J Clin Pharmacol. 1994;38:205-12.

36. Babalola CP, Kotila OA, Dixon PAF, Oyewo AE. Disposition of quinine and its major metabolites, 3-hydroxyquinine in patients with liver diseases. Res Pharm Biotech. 2011;3:25-9.

37. Mimche SM, Lee CM, Liu KH, Mimche PN, Harvey RD, Murphy TJ, et al. A non-lethal malarial infection results in reduced drug metabolizing enzyme expression and drug clearance in mice. Malar J. 2019;18:234.

38. Davis TM, White NJ, Looareesuwan S, Silamut K, Warrell DA. Quinine pharmacokinetics in cerebral malaria: predicted plasma concentrations after rapid intravenous loading using a two-compartment model. Trans $\mathrm{R}$ Soc Trop Med Hyg. 1988;82:542-7.

39. Miyagi SJ, Collier AC. The development of UDP-Glucuronosyltransferase $1 \mathrm{~A} 1$ and $1 \mathrm{~A} 6$ in the pediatric liver. Drug Metab Dispos. 2011;39:912-9.

40. De Wildt SN, Kearns GL, Leeder JS, van den Anker JN. Cytochrome P450 3A: ontogeny and drug disposition. Clin Pharmacokinet. 1999;37:485-505.

41. Kadam PP, Gogtay NJ, Karande S, Shah V, Thatte UM. Evaluation of pharmacokinetics of single-dose chloroquine in malnourished children with malaria: a comparative study with normally nourished children. Indian J Pharmacol. 2016;48:498-502.

42. White NJ, Looareesuwan S, Warrell DA, Warrell MJ, Bunnag D, Harinasuta T. Quinine pharmacokinetics and toxicity in cerebral and uncomplicated falciparum malaria. Am J Med. 1982;73:564-72.

43. Aguree S, Gernand AD. Plasma volume expansion across healthy pregnancy: a systematic review and meta-analysis of longitudinal studies. BMC Pregnancy Childbirth. 2009;19:508.

44. USFDA. Qualaquin. Highlights of prescribing information. FDA product Label. 2013.

45. Evans MA, Triggs EJ, Cheung M, Broe GA, Creasey H. Gastric emptying rate in the elderly: implications for drug therapy. J Am Geriatr Soc. 1981;29:201-5.

46. Moore JG, Tweedy C, Christian PE, Datz FL. Effect of age on gastric emptying of liquid-solid meals in man. Dig Dis Sci. 1983;28:340-4.

47. Lee JS, Cheong HS, Kim LH, Kim JO, Seo DW, Kim YH, et al. Screening of genetic polymorphisms of CYP3A4 and CYP3A5 genes. Korean J Physiol Pharmacol. 2013;17:479-84.

48. Zhou XY, Hu XX, Wang CC, Lu XR, Chen Z, Liu Q, et al. Enzymatic activities of CYP3A4 allelic variants on quinine 3-hydroxylation in vitro. Front Pharmacol. 2019;10:591.

49. Saeheng T, Na-Bangchang K, Siccardi M, Rajoli RKR, Karbwang J. Physiologically-based pharmacokinetic modeling for optimal dosage prediction of quinine coadministered with ritonavir-boosted lopinavir. Clin Pharmacol Ther. 2020;107:1209-20.

50. Bjorkman A, Willcox M. In vitro susceptibility of Plasmodium falciparum to amodiaquine, mefloquine, quinine and chloroquine in Liberia, West Africa. Trans R Soc Trop Med Hyg. 1986;80:761-2.

51. Bjorkman A, Willcox M, Marbiah N, Payne D. Susceptibility of Plasmodium falciparum to different doses of quinine in vivo and to quinine and quinidine in vitro in relation to chloroquine in Liberia. Bull World Health Organ. 1991;69:459-65.

52. Sabchareon A, Chongsuphajaisiddhi T, Sinhasivanon V, Chanthavanich P, Attanath P. In vivo and in vitro responses to quinine and quinidine of Plasmodium falciparum. Bull World Health Organ. 1988;66:347-52.

53. Lim P, Wongsrichanalai C, Chim P, Khim N, Kim S, Chy S, et al. Decreased in vitro susceptibility of Plasmodium falciparum isolates to artesunate, mefloquine, chloroquine, and quinine in Cambodia from 2001 to 2007. Antimicrob Agents Chemother. 2010;54:2135-42.

54. Chaijaroenkul W, Bangchang KN, Mungthin M, Ward SA. In vitro antimalarial drug susceptibility in Thai border areas from 1998-2003. Malar J. 2005:4:37.

55. Huttinger F, Satimai W, Wernsdorfer G, Wiedermann U, Congpuong K, Wernsdorfer WH. Sensitivity to artemisinin, mefloquine and quinine of Plasmodium falciparum in northwestern Thailand. Wien Klin Wochenschr. 2010;122(Suppl 3):52-6.

56. Eisenhut M, Omari AA. Intrarectal quinine versus intravenous or intramuscular quinine for treating Plasmodium falciparum malaria. Cochrane Database Syst Rev. 2009;2009:CD004009.

57. Winstanley PA, Mberu EK, Watkins WM, Murphy SA, Lowe B, Marsh K. Towards optimal regimens of parenteral quinine for young African children with cerebral malaria: unbound quinine concentrations following a simple loading dose regimen. Trans R Soc Trop Med Hyg. 1994;88:577-80.

58. Wanwimolruk S, Denton JR. Plasma protein binding of quinine: binding to human serum albumin, alpha 1-acid glycoprotein and plasma from patients with malaria. J Pharm Pharmacol. 1992;44:806-11.

59. Pukrittayakamee S, Wanwimolruk S, Stepniewska K, Jantra A, Huyakorn S, Looareesuwan S, et al. Quinine pharmacokinetic-pharmacodynamic relationships in uncomplicated falciparum malaria. Antimicrob Agents Chemother. 2003;47:3458-63.

60. Verdier MC, Bentue-Ferrer D, Tribut O, groupe Suivi Therapeutique Pharmacologique de la Société Francaise de Pharmacologie et de Thérapeutique. [Therapeutic drug monitoring of quinine](in French). Therapie. 2011;66:507-16.

61. Miller L. Malaria. Philadelphia: Haper and Row; 1983.

62. WHO. Severe and complicated malaria. World Health Organization Malaria Action Programme. Trans R Soc Trop Med Hyg. 1986;80 Suppl:3-50.

63. Veering BT, Burm AG, Souverijn JH, Serree JM, Spierdijk J. The effect of age on serum concentrations of albumin and alpha 1-acid glycoprotein. Br J Clin Pharmacol. 1990;29:201-6.

64. Newton P, Keeratithakul D, Teja-Isavadharm P, Pukrittayakamee S, Kyle D, White N. Pharmacokinetics of quinine and 3-hydroxyquinine in severe falciparum malaria with acute renal failure. Trans R Soc Trop Med Hyg. 1999;93:69-72.

65. Fernandez L, Breinbauer HA, Delano PH. Vertigo and dizziness in the elderly. Front Neurol. 2015;6:144.

66. Zhuang $X$, Lu C. PBPK modeling and simulation in drug research and development. Acta Pharm Sin B. 2016;6:430-40.

67. Bains RK. African variation at cytochrome P450 genes evolutionary aspects and the implications for the treatment of infectious disease. Evol Med Public Health. 2013;1:118-34.

\section{Publisher's Note}

Springer Nature remains neutral with regard to jurisdictional claims in published maps and institutional affiliations. 